pain, set in the same evening; leeches were applied; active purging was resorted to; but without alleviation of his sufferings. After two days' torture he consulted another surgeon, who was equally unsuccessful with the first in discovering any foreign body, but neither of these gentlemen could have everted the upper lid. The patient stated to me that he was confined to bed three weeks, and severely salivated; but although the acute symptoms subsided, motion of the eye caused severe pain.

When I saw him, five weeks after the accident, he was much debilitated, and his teeth were loosened by mercury. The conjunctiva of the eye was of a purplish hue; the cornea hazy towards its upper part; and many vessels ramified upon it ; the iris dull and slightly discoloured; the vision imperfect.

The first thing, that I did was to evert completely the upper lid, and there I found a particle, apparently of coal, quite as large as a small pin's-head, firmly adherent to the conjunctiva of the palpebra, and imbedded in a sort of fungous growth. I picked it out with a cataract-needle, and the poor fellow immediately experienced the greatest relief. He said he felt " comparatively in heaven." The exciting cause of irritation being removed, the eye rapidly got quite well.

This case should teach a lesson to every surgeon which ought never to be forgotten, and will, I hope, leave a deep impression upon the minds of all who read it,--it requires no comment from me.

Tenterden-street, Hanover-square, Dec. 20, 1843.

\section{DEATH AFTER SWALLOWING}

\section{THE}

\section{INFLAMMABLE TIPS OF LUCIFER} MATCHES.

To the Editor of THE LANCET.

SiR, - I beg to forward to you, for insertion in The Lancer, the subjoined case which has lately occurred in $\mathrm{my}$ practice, and which I consider valuable, not only from the fact that few, if any, similar cases have been recorded, but, also, from the anomalous symptoms that were observed during life, as well as from the very unusual appearances which were exhibited at the post-mortem examination. I remain, Sir, yours very obediently,

\section{Union-street, Stonehouse,}

James Shephard. Dec. 15, 1843.

On Monday evening last a poor woman brought her child, aged two years and four montlis, to my house, informing me that on the previous Thursday, while kissing her child, she observed her breath to smell of lucifer matches. However, as the child was not at all unwell, she contented herself with mentioning her suspicion to her husband, The child continued well all day on Friday and Saturday. On Sunday, although she seemed poorly, she ate a hearty breakfast. The father this morning discovered eight lucifer matches with the ends bitten off. On Sunday evening the child was taken to chapel, though she appeared rather heavy and drowsy. On Monday she still appeared very unwell, but without any prominent symptoms. On being pressed she stated that she had sucked the lucifers. As she became worse towards the evening she was brought to me for advice. She was lying in her mother's arms, exhibiting a disinclination to move. She had a little feverish excitement, but there was a total absence of active symptoms. The bowels had been opened, but not purged ; there had been no vomiting, no complaint of pain. I questioned the parents especially as to the probability of the child having on that day (Monday) sucked the matches, but they assured me that it was impossible the child could have obtained them since the Thursday. I recommended a little oil, and expressed my opinion that this was not a case of poisoning by phosphorus, and that the lucifer matches were not the cause of the illness. In about five hours from my first seeing the child I was called out of bed to attend her. She was violently convulsed, and altogether in a very alarming condition. I left with the conviction that the illness and convulsions were but coincidences. The child died about three hours after my visit, and an inquest was held on the body, when $I$ informed the jury that although I could give no decided opinion on the case still I believed that the death was but a coincidence, and was not the result, of the taking phosphorus. The jury then adjourned to give me time to make the required examination, when, to my great surprise, I found the following appearances:On opening the stomach, about half a wineglassful of mucus, intermixed with blood, resembling coffee-grounds, escaped. The mucous membrane of the stomach was, generally, highly vascular, and there was an abnormal quantity of mucus secreted and attached to the mucous membaane. There was an irregularly-defined space, covering about two inches in extent, of a florid red colour, on the surface of which was a thick collection of mucus, intermixed with which was "coffee-ground" blood, presenting the appearance of having been simultaueously secreted. On holding the stomach to the light its vessels were seen to be gencrally much dilated. The most singular appearances were in the intestines. They were such as I can account for only on the supposition of powerfal reversive action, but where were the symptoms during life? Throughout the small intestines $I$ found ten invaginations, many of which included 
from two to three inches of intestine, which was inflamed at the invaginated parts. None of these appeared to be strangulated. The bowels were, generally, empty. Two of these invaginations were found in the duodenum, the remaining number in the rest of the small intestines.

The verdict, which was arrived at, and in which I fully agreed, was, that the deceased died from the effects of lucifer matches. I consider that the phosphorus, which exists in them in a minutely divided state, had attached itself to the mucous membrane of the stomach, and excited inflammation of that organ by virtue of its chemical action.

\section{REPLY OF MR. WAKEFIELD TO MR, ROTCH.}

\section{To the Editor of The Lancet.}

Sir,-My attention having been called to Mr. Rotch's statement in THE LANCET, of last week (page 354), I beg to offer some remarks upon the case, and to enter upon an explanation which I hope will prove satisfactory to the profession and relieve me from certain imputations which are quite unmerited, and display, on Mr. Rotch's side, a misapprehension of my behaviour, which, I must confess, has greatly surprised me. I enter upon my own justification only, leaving Dr. Hamilton Roe to conduct his own defence, if he thinks fit, at the same time premising that no misunderstanding exists between the Doctor and myself, and that no difference of opinion in the treatment of the case was at any time made manifest. One act of $\mathrm{Mr}$. Rotch surprises me greatly. After castigating, in no measured terms, the editors of the " Provincial Medical Journal," for their indelicate introduction of his relative's name upon anonymous information, he shows a degree of delicacy in not disturbing the incognito of the correspondent signing himself "M.D.," which, to me, is unaccountable. I am most anxious to know how "M.D." became possessed of the facts, the medical facts, connected with this case. Who could have furnished the medical phraseology in which the history is clothed?

I now proceed to a narrative of the case as it occurred, and I hope my veracity, from the station $I$ hold in the profession, will be fully relied upon.

On the 26th of June I was requested to see the highly respectable relative of $\mathrm{Mr}$. Rotch. I had attended several branches of the family before, but she had never required my assistance, her general health and constitution, for the age of seventy-nine, being unusually good, and she always expressing herself as placing little faith in medicine. She had returned from Bath a few days before, having been suffering whilst there from the complaint I was called in to prescribe for, namely, bilious continued fever with dis. tressing diarrhoea. The usual routine of medicine was prescribed, but without pro. ducing any impression upon the complaint, acd on the third day, the family becoming alarmed, but without giving me any intimation of their intention, requested Dr. Hamilton Roe's attendance. He arrived in my absence, and finding that $I$ had taken charge of the case, very properly refused to interfere in the treatment till we could meet in consultation. We met in the evening, and some alteration was made in the treatment, which was varied from time to time, the diarrhoea and fever receiving occasioual checks, but never being subdued. We continued our attendance till Saturday, the 15th of July, the invalid having taken several drives in a carriage round the park during the preceding days. On this day Dr. Roe suggested the use of an opiate enema, which, however, did not arrest the diarrhoea, but produced considerable stupor, which increased on the two following days. No medicine of any kind was given after the 15th. Soda water and brandy, aud nutritious broths, were the only things taken. On Monday evening the prostration of strength, accompanied with profuse perspiration and cold extremities, rendered the patient's case one of extreme danger.

It was on this occasion that Mr. Rotch, after asking Dr. Roe and myself whether more could be effected from medicine, received the reply. "at present, certainly not." Upon hearing this opinion, he expressed bis determination of resorting at once to the bydropathic treatment, first requesting that we should both remain upon the spot, lest any alarming consequences might result from so hazardous an experiment. Now comes the part of Mr. Rotch's narrative which has both surprised and mortified me, and which I as distinctly disclaim as he has emphatically asserted it. He says,

"With a due dread of the sneers of their brotherhood, both gentlemen refused to consent to anything of the kind, and it was with the greatest difficulty they were persuaded to remain in the house while the first appli. cation of the damp liuen was made."

My consent was neither asked nor required. Why should it have been? When Mr. Rotch determined upon pursuing his own treatment, my answer, I remember perfectly well, was to this effect:-"I have no objection whatever to remain, but having no experience of the hydropathic treatment, I beg to relieve myself from all responsibility attending it." I remained in the house half an hour, witnessed the application of the damp linen, and saw the patient covered with blankets, felt her pulse, and, finding no change in her symptoms, left the house. We met again on the next morning, the symptoms remaining much the same. On the following day the diarrhoea and fever had subsided, to a certain extent, and a gradual 